\title{
Desplegando la estación del abanico: la poesía de senectud de Pilar Paz Pasamar ${ }^{1}$
}

\author{
Paulo Antonio GATICA COTE \\ Universidad de Salamanca \\ paulo.gaticacote@gmail.com
}

\begin{abstract}
RESUMEN
Este trabajo pretende analizar la producción poética de senectud de la creadora andaluza perteneciente a la Generación del 50 Pilar Paz Pasamar (1933). Tras más de una década de silencio después de un comienzo fulgurante con la aparición de seis poemarios en poco más de quince años, Paz Pasamar ha publicado cinco libros - La torre de babel y otros asuntos (1982), Textos lapidarios (1990), Philomena (1995), Sophía (2003) y Los niños interiores (2008) - que ahondan en sus inquietudes iniciales y a las que añade nuevos y renovados matices. A este propósito, se recuperará el sintagma "poesía de senectud" como concepto teórico pertinente para el estudio de la obra de poetas con una dilatada trayectoria. Este análisis comprenderá, por tanto, las plasmaciones formales y temáticas ligadas al "envejecimiento" de la voz poética de Pilar Paz Pasamar.
\end{abstract}

Palabras clave: Poesía femenina, Generación del 50, Pilar Paz Pasamar, Poesía de senectud.

\begin{abstract}
This paper will try to survey the poetry written by the andalusian Pilar Paz Pasamar (1933) member of the 50's Generation- in her old age. After a brilliant start, with the revelation of six works in nearly fifteen years, Paz Pasamar remained silent for more than a decade. Then, since 1982, Paz Pasamar has published five books -La torre de babel y otros asuntos (1982), Textos lapidarios (1990), Philomena (1995), Sophía (2003) and Los niños interiores (2008) - that delve into her initial concerns and add new and renovated aspects to her poetry. We will focus on the "old age poetry" as a relevant theoretical concept to study the work of poets with a long career. Therefore, this analysis will include the formal and thematic expressions related to the "aging" of the poetic voice of Pilar Paz Pasamar.

Key words: Women's poetry, Generation of 1950, Pilar Paz Pasamar, Old age poetry.

\footnotetext{
${ }^{1}$ Este trabajo se encuadra dentro de las labores de investigación derivadas de la condición de beneficiario del programa de becas y ayudas a la Formación de Profesorado Universitario (FPU) del Ministerio de Educación español.
} 
Sumario: 1. Introducción 2. ¿Poesía última o poesía de senectud? 3. "Desplegando la estación del abanico": la poesía de senectud de Pilar Paz Pasamar 4. Conclusiones

\section{Introducción}

El abanico es un objeto cargado de simbolismo, poseedor de un lenguaje propio que ha sido ampliamente tematizado por diferentes discursos artísticos. Habitualmente ligado a la sociedad de la corte, el abanico sirve a Pilar Paz Pasamar como motivo para desplegar en un hermoso ensayo titulado La mujer y la poesía de lo cotidiano (1964) las primeras manifestaciones de "poesía femenina de las cosas". Entre otros ejemplos, la poeta gaditana cuenta la anécdota de Pan Tsieh-yu, favorita del emperador Chengti, quien recibe un pequeño abanico al ser relegada de su privanza por una mujer más joven y que en el siglo I a.C. "dejó para siempre una deliciosa, delicada muestra de la sensibilidad femenina de su creadora":
Más, ¡ay de mí!, por fin llega el solsticio
y del viento otoñal soplan las voces.
Ya se acabó el verano
y el caluroso sol desaparece.
Entonces, mi señor, el abanico
abandona en el fondo de una caja;
ya ni sirve ni agrada,
terminó la estación del abanico. ${ }^{2}$

La elección de la poeta gaditana Pilar Paz Pasamar para el estudio de su poesía de senectud no es fortuita. A lo largo de más de cincuenta años, la autora ha publicado once libros de poesía -el duodécimo se encuentra bastante avanzado-, y aparecido en numerosas antologías. ${ }^{3}$ Sin duda, es una de las grandes voces vivas del medio siglo ${ }^{4}$ y una de las peor estudiadas, aunque en la última década ha suscitado

2 P. Paz Pasamar (1964), p. 5. El próximo poemario de Paz Pasamar se titulará reveladoramente "La estación del abanico" del que ya se ha publicado en revista un poema homónimo: "Por la manera que sonríes/ sé que sueñas con ella./ Por la abertura de los labios/ se te escapa el vagido de su nombre./ Por las varillas de tus dedos,/ abanico extendido en el embozo, / aspiro el aire de su primavera./ Con tu estremecimiento, me estremezco,/ tu corazón, tu cuerpo junto al mío,/ tan a la vez, unísonos y al paso,/ tú amando y yo aprendiendo cómo amas". P. Paz Pasamar (2007), p. 48.

3 Un listado bibliográfico bastante completo de la autora puede encontrarse en la página dedicada a Pilar Paz Pasamar en el Centro Virtual Cervantes: http://cvc.cervantes.es/actcult/paz_pasamar/default.htm.

${ }^{4}$ Utilizaré indistintamente las etiquetas "medio siglo", "Generación de los 50", "Segunda generación de posguerra", "promoción de los 50", etc. El uso libre de los términos no 
un interés creciente gracias a las contribuciones nada desdeñables de especialistas tales como Sharon Keefe Ugalde, Ana Sofía Pérez-Bustamante, José María Balcells, José Ramón Ripoll o Manuel Francisco Reina. Además, le han sido dedicados dos números monográficos en las revistas Extramuros y RevistAtlántica de poesía y la creación de un portal en la web del Centro Virtual Cervantes dentro de la sección de "Nombres propios". A estos esfuerzos habría que sumar la reciente edición de las poesías completas de Pilar Paz Pasamar a cargo de la profesora de la Universidad de Cádiz Ana Sofía Pérez-Bustamante. ${ }^{5}$

\section{2. ¿Poesía última o poesía de senectud?}

Hay un peligro inmediato cuando se habla de poesía de senectud y es, en mi opinión, la falta de concreción teórica. El sintagma "poesía de senectud" se utiliza como una noción hueca, un recurso de críticos para nombrar la producción creadora en la vejez, por lo que muchas veces se emplea como sinónimo de poesía última. La poesía última, si se revisan los enunciados de algunos textos especializados, remite a dos circunstancias: la última publicación -o publicaciones- de un autor independientemente de su edad o de los últimos libros publicados en vida de un autor. Esta última acepción se acercaría más al concepto teórico que se va a seguir en este trabajo; sin embargo, la poesía de senectud es un fenómeno complejo que comprende más factores que la producción final del poeta.

El análisis de la poesía de senectud es un terreno relativamente nuevo por la escasez de precedentes más que por la actualidad de los mismos. La obra que sienta las bases para este tipo de estudios salió de imprenta en 1988 con el título de Poesía de senectud. Guillén, Diego, Aleixandre, Alonso y Alberti en sus mundos poéticos terminales $^{6}$. En primer lugar, Díez de Revenga marca un límite temporal en torno a los setenta años que se correspondería a la "vejez" del poeta. No aclara los motivos de tal asignación y más bien parece que busca una edad representativa de la denominada poesía de senectud ${ }^{7}$. No obstante, sí especifica que este tipo de indagaciones sólo pueden llevarse a cabo poniendo en relación "la realidad material del poema creado con la propia realidad biográfica de este poeta"»; es decir, la poesía de senectud no depende de la cronología del poeta, sino de cómo se materializa la experiencia biográfica de la vejez en el poema. No hay que olvidar

implica mi adhesión -ni mi rechazo al criterio generacional- a cualquiera de las propuestas de la crítica.

${ }^{5}$ P. Paz Pasamar (2012a). Este trabajo se completa con la publicación de la obra en prosa de Paz Pasamar a cargo de la profesora de la State University de Colorado Ma . López Cabrales (2012).

${ }^{6}$ Previamente, Francisco Javier Díez de Revenga había publicado un artículo temprano que abordaba la temática de senectud. F. J. Díez de Revenga (1977), pp. 39-46.

${ }^{7}$ F. J. Díez de Revenga (1988), pp. 11 y ss.

${ }^{8}$ F. J. Díez de Revenga (1988), p. 28. 
que el ensayo profundiza en algunos escritores de la Generación del 27. Es, en puridad, un ejercicio comparativo que busca sistematizar las inquietudes fundamentales rastreables en los textos crepusculares de estos autores y que considera características de la poesía de senectud, a saber': la edad, la vejez, las mutaciones de la naturaleza, la muerte, el insomnio, la transitoriedad, el viaje, el camino en relación con la idea de destino, la lucidez final, la memoria, la elegía de la juventud desde la vejez, el cansancio o la soledad. ${ }^{10}$

Evidentemente, no todos los poetas viven la experiencia de la vejez del mismo modo. Creo que se puede hablar de poetas que, por distintas razones, se mueven en registros paradójicos para su edad: jóvenes que viven en la elegía y mayores que cantan la plenitud del invierno -se ha llegado a hablar de cierto "narcisismo senil" en algunos autores-. ${ }^{11}$ Quizá, la demostración más visible de la temática de senectud se encuentre en los recovecos de la poesía escrita por mujeres, donde la decadencia del cuerpo parece recrearse con más intensidad. ${ }^{12}$ De acuerdo con Simone de Beauvoir:

Hayamos encontrado una imagen más o menos convincente, más o menos satisfactoria de nosotros mismos, esa vejez que somos incapaces de realizar,

${ }^{9}$ En última instancia, el objetivo del ensayo es plasmar la existencia de reacciones comunes en los escritores de la Generación ante la llegada de la vejez: "se ha tratado de explicar en su totalidad el mundo poético creado por el autor a partir de ese año o de ese libro, y una vez sistematizados los motivos que conforman esa determinada poesía, se ha puesto en relación con los textos ya analizados o por analizar del resto de los poetas". F. J. Díez de Revenga (1988), pp. 27-28. En un artículo posterior aclara algo más: "El paso del tiempo, la fuerza del devenir vital y su propia existencia lanzan al poeta en los años quizá últimos de su vida, a su consideración, a su reflexión espiritual, y, desde allí su palabra, su voz, su transmuta en una serie de motivos, de nuevos impulsos que inician un nuevo universo imaginístico, un nuevo mundo poético". F. J. Díez de Revenga (1989), pp. 177-78.

${ }^{10}$ Los títulos escogidos por muchos creadores "de senectud" son generalmente muy esclarecedores. Por ejemplo y sin ánimo de ser exhaustivos: Vicente Aleixandre, Poemas de la consumación; León Felipe, Puesto ya el pie en el estribo; Ángel González, Otoños y otras luces; Jaime Gil de Biedma, Poemas póstumos.

${ }^{11}$ Gutiérrez Estupiñán estima que este "narcisismo senil" es predominantemente masculino y no se aprecia en el discurso femenino. R. Gutiérrez Estupiñán (1997), p. 161.

${ }^{12}$ Los psicólogos han catalogado este tipo de actitudes hostiles ante la vejez como Age-ism: "La imagen de la persona de edad, en nuestra sociedad, sigue estando caracterizada hoy día por la constatación de la soledad y el aislamiento, de la dependencia y de la necesidad de ayuda, y también por la decadencia y pérdida de capacidades y habilidades". U. Lehr, H. Thomae (2003), p. 285. La noción de "age-ism" fue acuñada por el doctor Robert N. Butler y definida en los siguientes términos: "age discrimination or age-ism, prejudice by one age group toward other age groups". R. N. Butler (1969), p. 246. 
tenemos que vivirla. Y ante todo la vivimos en nuestro cuerpo. No es él el que nos la revela; pero una vez que sabemos que la habita, nos inquieta. ${ }^{13}$

La crítica feminista ha argumentado que esta devaluación del cuerpo femenino es resultado de la reafirmación del poder simbólico ejercido por una cultura patriarcal ${ }^{14}$.

En esta línea, Susan Sontag postula en un artículo fundacional la existencia de un desequilibrio o doble patrón en la sociedad a la hora de enfrentarse a la certidumbre del envejecimiento -que no a la vejez-:

But the objective, sacred pain of old age is of another order than subjective, profane pain of aging. Old age is a genuine ordeal, one that men and women undergo in a similar way. Growing older is mainly an ordeal of the imagination -a moral disease, a social pathology- intrinsic to which is the fact that it afflicts women much more than men. It is particularly women who experience growing older (everything that comes before one is actually old) with such distaste and even shame $e^{15}$.

La ensayista estadounidense subraya que la exaltación de los valores asociados a la juventud es producto de sociedades capitalistas, cuyos ritmos de vida vienen marcados por la producción desmedida, el consumo acelerado y el cultivo de un imaginario neo-narcisista. ${ }^{16}$

Todos los indicios expuestos apuntan a que este tipo de enfoques es muy necesario para completar ese extraño y traicionero puzle que suele ser la poesía; sin embargo, el estudio de la poesía de senectud no ha tenido continuación -con contadas excepciones- a pesar de la pertinencia de un análisis serio por la longevidad de muchos poetas de primer orden y la relevancia de sus "mundos poéticos terminales"17. De todas formas, estimo necesario plantear algunos presupuestos de partida para una posible metodología:

\footnotetext{
${ }^{13}$ S. Beauvoir (1989), p. 360.

${ }^{14}$ Apud. R. Gutiérrez Estupiñán (1997), pp. 152-163.

${ }^{15}$ S. Sontag (1972), p. 29.

${ }^{16}$ S. Sontag (1972), p. 31. Sostiene Gilles Lipovestsky que "el miedo moderno a envejecer y morir es constitutivo del neo-narcisismo: el desinterés por las generaciones futuras intensifica la angustia de la muerte, mientras que la degradación de las condiciones de existencia de las personas de edad y la necesidad permanente de ser valorado y admirado por la belleza, el encanto, la celebridad hacen la perspectiva de la vejez intolerable". G. Lipovetsky (2011), p. 61.

17 Biruté Ciplijauskaité invita directamente a la exploración de esta vía: "Podría resultar interesante un estudio que comparara la actitud de autoras como Atencia, Fagundo y Janés, quienes, al acercarse a "la edad crítica", sienten aumentar su potencial creador, y los últimos
} 
1) El poema, por muy ligado a la experiencia vital del autor que esté, debe ser valorado como una obra de ficción.

2) La "verdad" de la obra queda suspendida mediante un acuerdo o "pacto lírico" entre el creador y el receptor. ${ }^{18}$

3) El estudio de la poesía de senectud tiene que considerar las manifestaciones temáticas y formales de la vejez en el poema.

4) Se considerarán las expresiones de senectud de diversas áreas culturales para establecer una base de comparación útil.

\section{Desplegando la estación del abanico: la poesía de senectud de Pilar Paz Pasamar $^{19}$}

Pilar Paz Pasamar ha lanzado al mercado en las tres últimas décadas varios libros que añaden renovados matices a una trayectoria que pareció ralentizarse a finales de los sesenta tras un arranque fulminante. Entre 1951 y 1967 publica seis libros: Mara (1951), Los buenos días (1954) -Finalista del Premio Adonais de Poesía de 1953-, Ablativo amor (1955) -Premio Juventud-, Del abreviado mar (1957), La soledad contigo (1960) y Violencia inmóvil (1967). Violencia inmóvil es un libro bisagra en muchos sentidos. Aunque se imprime en 1967, ya desde 1958 se van presentando algunos poemas en diversas publicaciones. ${ }^{20}$ Esta fecha situaría teóricamente el origen del poemario entre Del abreviado mar (1957) y La soledad, Contigo (1960), en pleno traslado de Madrid a Cádiz. Sobre el libro adelanta su amigo Fernando Quiñones:

Muy expresiva, empapada de intuición vital, la poesía de Pilar Paz, cuyos temas habituales se centraron en constantes motivaciones de la lírica femenina -el amor, la maternidad, la vida diaria-, (aparecen) nuevos y sensibles aspectos de crítica y

libros de autores como Jenaro Talens o Andrés Trapiello, donde transparece el tema de la "vejez" en términos menos afirmativos.". B. Ciplijauskaité (2004), p. 330.

${ }^{18}$ A partir del concepto de "pacto narrativo" planteado por Pozuelo Yvancos, propone Juan María Calles en su tesis doctoral el "pacto lírico": "la aceptación de este pacto de ficción o pacto lírico supone también la aceptación por parte del lector de las estrategias de enunciación (autor) y recepción (lector) que el texto plantea en su proceso de fictivización mediante el desdoblamiento de la estructura comunicativa y la propuesta de suspensión al receptor de las condiciones de verdad reales que se efectúa en todo proceso de comunicación artística". J. M. Calles Moreno (2002), p. 140.

${ }^{19}$ Todas las citas de poemas en este artículo se corresponden a las ediciones señaladas en la bibliografía final.

${ }^{20}$ Cinco poemas publicados en una separata del número 120-121 de Archivo Hispalense (1958) y otros cinco en el 169 de Cuadernos Hispanoamericanos (1964). Los textos presentan variantes significativas respecto a la edición final del texto, incluida la supresión de una de las composiciones: "Dichosa orilla del dolor". 
revisión sociomoral, sin pérdida de sus características de origen, esencialmente líricas. $^{21}$

Ciertamente, con Violencia inmóvil "la autora se introduce en los espacios oscuros y difíciles de la poesía, donde, por primera vez, se va a aventurar en los terrenos de la ambigüedad"22. Supone un salto respecto a su producción anterior. La voz conserva el fondo existencial pero la mirada abarca más territorio, el poema respira con libertad y es capaz de amoldarse a nuevos escenarios. Ahora tienen cabida el verso libre o medido, la experiencia del yo en su circunstancia, la indefinición de la palabra creadora o el juego. El misterio sigue latiendo debajo de la epidermis pero la poeta siente que ha alcanzado una madurez que le permite contemplar el mundo con perspectiva suficiente: "Con más amor que todo el que he sentido/ yo me detengo en medio de la vida./ Todo tiene mejor diafanía" (36).

La tercera sección del poemario desvela, a diferencia de la producción anterior, una profunda crisis de fe. El tono es marcadamente patético, lleno de interrogaciones retóricas y apóstrofes desesperados (64): “¿Qué te parece lo que estás haciendo?/ ¿Por qué me dejas? ¿Para qué consientes?/ Dudo de Ti, Señor, estoy dudando.../¿Es que es mi duda lo que Tú prefieres?”. Al final, tras varios poemas de enfrentamiento con Dios, la poeta se humilla ante la creación y alaba "guilleneanamente" el universo: "Y todas tus palabras están arrodilladas,/ y mientras haya algo arrodillado,/ junto a Dios, más pequeño, todo sigue existiendo,/ todo sigue creciendo.../ ¡Todo en el universo/ tiene razón de ser y está en su sitio!” (71).

Quince años de silencio median entre Violencia inmóvil (1967) y su siguiente libro La torre de Babel y otros asuntos (1982); quince años de transición entre una primera etapa más próxima a las líneas poéticas del intimismo existencial de la poesía de posguerra que a la voz más madura y abierta, en sintonía con los avances de los movimientos poéticos de su generación -poesía del conocimientopresentida en Violencia inmóvil y confirmada en el poemario siguiente. La torre de Babel se estructura en dos partes muy diferenciadas: la primera -auténtico núcleo poemático- sin título y "Torre del homenaje". En la primera parte, predomina en términos de Ana Sofía Pérez-Bustamante la "reflexión en torno a la circunstancia del sujeto poético y del mundo actual, tan cambiado en el tiempo que va de 1967 a 1982"23; en la segunda, Paz Pasamar cambia de registro y homenajea a amigos y lugares relevantes para la autora: José María Pemán, Julio Mariscal, Trina Mercader, San Juan de la Cruz, Juan Ramón Jiménez, El Puerto de Santa María o Cádiz. La amistad, tema muy frecuente en la poesía de senectud del siglo XX,

${ }^{21}$ F. Quiñones (1966), p. 59.

22 J. M. Balcells (1986), p. 15.

${ }^{23}$ A. S. Pérez-Bustamante (2005). 
especialmente, en poetas de la Generaciones del 27 como Dámaso Alonso, Jorge Guillén o Rafael Alberti, es concebida como

Una manera de sobrevivir al tiempo en esta poesía de senectud es vincularlo al recuerdo de personas cercanas. El gran vínculo de amistad une a las personas y permanece sobre el tiempo. (...) La amistad, por otra parte, se engrandece y adquiere mayor solera con los años, y cuanto más antigua, más remota, mayor es su valoración y su significación humana. ${ }^{24}$

El primer poema introduce una de las grandes preocupaciones de la lírica de la autora jerezana: la reflexión sobre la palabra poética. En este texto, la crisis de la palabra -el propio silencio de la autora durante quince años- aparece simbolizada por el derrumbamiento de la torre bíblica (11): "La torre cayó al suelo, volvió al seno la arcilla/ y en silencio la tierra lloró por la palabra...". Las imágenes encadenadas y la fragmentación del discurso inauguran un universo sin referentes claros, alejado de los tonos jubilosos y las afirmaciones sin rugosidades que abundaban en sus primeros poemarios y que poblarán su lírica a partir de Philomena. Predomina en esta sección el tono crispado, las figuras patéticas anticipadas en Violencia inmóvil- a un "tú" salvador y la incapacidad del verbo (16): "Abandoné el jardín, sus consecuencias,/ sus juegos, sus nostalgias. Quise ser/ y salí, como otros... ¿Y por qué? (...)/ Diste el grande grito/ Descomunal, abiertas las quijadas,/ Espantosa llamada insobornable:/ ¡Tú, tú, tú, tú, tú, tú, tú, tú, tú, tú!/... ¿Y ahora qué?". No obstante, incluso perdido el rumbo, Paz Pasamar es consciente de que "la esperanza, ronda..." (15), existe esa puerta a la que llamar y "refugios interiores" $" 25$-tiendas, apartamentos, ascensores- extraídos de la realidad cotidiana en los que cobijarse y reflexionar. El poema "El ascensorista" (21-22) anticipa algunas de las ideas clave de la escritura de senectud de la poeta, a saber: la muerte como circunstancia inevitable pero incomparable con el "misterio",26 de la vida:

Tú tienes uniforme. Tú mandas en la nave.

Puedes hacer y deshacer en tu silencio,

y hacerte el sordo ante cualquier llamada.

Te puedes rebelar: ponerte, ya de espaldas, ya de frente,

\footnotetext{
${ }^{24}$ F. J. Díez de Revenga (1988), p. 99.

${ }^{25}$ Cfr. "La alacena". Paz Pasamar (1960), pp. 41-43. Paz Pasamar prefiere centrar la mirada en los espacios domésticos, en los pequeños objetos cotidianos. La casa y sus enseres son espacios de igual valor que cualquier otro para adentrarse en el misterio: "Porque cantar lo pequeño y sugeridor y transformarlo puede ser un hallazgo". P. Paz Pasamar (1964), pp. 2-3. En este poemario los espacios siguen siendo predominantemente interiores aunque fuera del ámbito doméstico.

26 "Hay algo que nos pasa inadvertido,/ algo que nos transita y que no vemos./ Borges lo llama ‘Aleph', y los sencillos/ le llamamos misterio”. P. Paz Pasamar (1967), p. 9.
} 
y seremos nosotros tripulación efímera, anodinos transeúntes, cargas a repartir.

Esta concepción de la vida como experiencia efímera frente a la perdurabilidad de un mundo bien hecho se ve reforzada por la puesta en valor de lo caduco. Pilar Paz Pasamar canta la hermosura y dignidad de la decadencia: "Por qué lo más hermoso está de moho/ cubierto, los cubiertos con verdines,/ la esquina sin calor y el labio amargo./ Por qué nuestro entusiasmo se apoca en la madera" (19). Aun así, la voz poética apetece "las zonas verdes, blandas de la tierra,/ sus paisajes tan dulces y lejanos" (26).

La salida del maremágnum diario, de la crisis existencial y poética se percibe tímidamente en los versos finales de "Quien lo probó lo sabe" (31): "Esperar... Ya lo supo el que lo supo/ a que surja de pronto en el momento/ inesperado de la llamarada/ decisiva, salir hacia su encuentro.../ ¡Abrazo que compendia los sabores/ únicos, vivos, válidos del Verbo!". Paz Pasamar se reafirma en su condición de poeta, regresa tras un largo peregrinar por el desierto (35): "Y fue mi estrella temporera/ con su dedo gastado/ quien me dijo: regresa. (...) Hacen como si no oliesen mi tufo/ de animal impregnado en el olvido,/ cómplices, reidores... ¡Porque he vuelto!"27. En estas piezas más "beligerantes", el insomnio ${ }^{28}$, asociado a la carencia o dificultad del sueño que suelen experimentar las personas a determinada edad, es uno de los motivos más poetizados por los artistas de senectud tal como explica en su estudio Díez de Revenga: "la realidad física del insomnio, habitual en la ancianidad, contribuye poderosamente a interminables espacios de meditación" 29 . Así, Jorge Luis Borges en un hermoso poemario dedicado a la efeméride de sus ochenta años, La cifra, escribe elocuentemente:

¿Qué es la longevidad? Es el horror de ser en un cuerpo humano cuyas facultades declinan, es un insomnio que se mide por décadas y no con agujas de acero, es el peso de mares y de pirámides, de antiguas bibliotecas dinastías, de las auroras que vio Adán, es no ignorar que estoy condenado a mi carne, a mi detestada voz, a mi nombre, a una rutina de recuerdos, al castellano, que no sé manejar, a la nostalgia del latín, que no sé, a querer hundirme en la muerte y no poder hundirme en la muerte, a ser y seguir siendo. ${ }^{30}$

27 Es muy probable que el poema "La vuelta (parábola del hijo pródigo)" se refiera irónicamente a su regreso a la poesía después de más de una década sin publicar.

${ }^{28}$ Vid. "El insomne (Apartamento 26-2)": "Ya no sabré qué hacer con las cuartillas/ ni, cuando ellas me falten, con mis pasos./ Ya no puedo saber si son objetos/ todo lo que perdí en la vida". P. Paz Pasamar (1982), p. 17.

${ }^{29}$ F. J. Díez de Revenga (1988), p. 94.

${ }^{30}$ J. L. Borges (1981), p. 29. 
El yo poético, tras indagar en la vigilia de la realidad en busca de respuestas, redescubre aquello que había olvidado después de la confusión inicial, ese tú indefinido al que imprecaba se convierte ahora en "Dios, Padre nuestro siempre compasivo,/ Roca donde se agarra la esperanza" (38). El entendimiento final supone la superación definitiva del aislamiento y la incomunicación tras el colapso de la torre de Babel: "-iSe entienden, mira, se entienden los hombres!" (41).

La segunda sección de La torre de Babel contrasta formal y temáticamente con la primera. En estas composiciones, el yo poético reflexiona en torno a la familia ${ }^{31}$, los amigos y la práctica de la poesía. La maternidad y, posteriormente, la llegada de nuevos descendientes que, en palabras de Díez de Revenga es "el gran premio del longevo personaje" 32 , cobra gran relevancia en la poesía de Paz Pasamar a partir de este poemario. En el fondo de este asunto subyace el debate entre actitud femenina y actitud feminista, cifrada por Keefe Ugalde en un conflicto determinado por "la tensión (...) de escoger entre ser buena poeta o ser buena madre y esposa" ${ }^{33}$. Biruté Ciplijauskaité postula que existen tres actitudes principales en la poesía femenina:

Hay un número de poetas que no declaran guerra a la tradición: conservan la actitud que se solía considerar femenina, pero sin incurrir en sentimentalismos; es una inmersión en los tópicos tradicionales a sabiendas, acentuando la fuerza de la femineidad. Por otra parte, existen aquellas que se rebelan, adoptando el tono irónico y hasta cínico. La poesía de éstas está teñida de escepticismo; la de aquéllas no ha renunciado a la nota afirmativa y tiende a la trascendencia. Una tercera dirección -o sub-dirección- sería la inversión 'a lo humano' de tópicos sagrados; incluso aquí habrá que distinguir entre intención afirmativa y negativa. ${ }^{34}$

La actitud de la poeta se corresponde a ese primer tipo de poesía que, sin renegar de la tradición, se sirve de ésta para expresar un universo poético "afirmativo y tendente a la trascendencia". Paz Pasamar aboga por la "Poesía" que no renuncia a su femineidad ni a la realización personal de la mujer mediante la maternidad; rechaza, por tanto, la poesía combativa feminista centrada en la deconstrucción del pensamiento falocéntrico y en la "mímesis crítica" de los discursos predominantes.

La composición con la que finaliza La torre de Babel, "Tú, mi blanca gaviota del después", es quizá la primera ocasión en la que aparece mencionada abiertamente la certidumbre del acabamiento ligado al topos mítico de Cádiz: "A ti me asomo, Cádiz, derrocada/ la confederación de aves marinas./ Sólo te cruzo ya

\footnotetext{
${ }^{31}$ Cfr. "Retrato de mis tres gracias graciosas": "Un varón y tres gracias,/ vaya regalo,/ sobre cuatro columnas,/ por duplicado./ (Que Hércules par tenía,/ un semidios)/ yo, soy sólo madre/ gano por dos". P. Paz Pasamar (1982), pp 70-72.

${ }^{32}$ F. J. Díez de Revenga (1988), p. 139.

${ }^{33}$ S. Keefe Ugalde (2007), p. 42.

${ }^{34}$ B. Ciplijauskaité (2004), p. 229.
} 
con la mirada,/ sin vuelos te persigo y te conozco./ Sé que eres mi final, donde antepongo/ esta inutilidad, toda esta prisa.// Tu luz, será la luz que me persiga.../ ¡Tú, mi blanca gaviota del después!” (83).

Un lapso de ocho años separa La torre de Babel de su siguiente publicación. Textos lapidarios $(1990)^{35}$ supone el primer conato culturalista de Paz Pasamar en su trayectoria, un libro que explora en la tradición andalusí ${ }^{36}$ y en la historia para comprender el presente. Siguiendo a Manuel Francisco Reina: "Pilar Paz indaga en esas tradiciones arabigoandaluzas que son su patrimonio natural, y se refleja en toda su obra, como en el poemario Textos Lapidarios basado en el Lapidario Alfonsí, versión a su vez de los libros sobre las propiedades de las piedras árabes y hebreos de al-Ándalus". ${ }^{37}$

El primer poema enlaza directamente con los versos finales ya citados de $L a$ torre de Babel y otros asuntos: "En Cádiz quiero que me entierren/ junto al mar, por los siglos de los siglos" (27). Alfonso X el Sabio, correlato objetivo y vehículo de expresión de la poeta, desea acabar sus días en su tierra natal. Llama poderosamente la atención el uso de una fórmula testamentaria al inicio del poema: "Yo, Alfonso,/ Rey castellano,/ hijo de Fernando,/ nieto de Berenguela,/ quiero ser enterrado junto al mar." (25). En la cultura japonesa existía la tradición de escribir ante la inminencia o la cercanía de la muerte pequeños poema-testamento, "poema a la despedida de la vida" o Jisei en los que se trasluce la fortaleza y el estoicismo del pensamiento zen. Para estos autores, la visión del final no es motivo para la elegía, sino para contemplación serena y el deleite sensorial de la naturaleza. ${ }^{38}$

A este tenor, "Piedra sepulcral" (53-55) es un curioso texto en el que José de Arimatea escribe una carta en tono coloquial a María Magdalena. Despliega "de oídas" la pasión de Jesucristo mediante varios recursos realistas como la referencialidad y la autorreferencialidad que potencian la declaración final de fe en la resurrección de la carne (55): "María: dile a Pedro, a Mateo y a Juan/ y a todos

\footnotetext{
${ }^{35}$ Sobre el origen del libro explica la autora lo siguiente: "fue una incitación de Sagrario Rodríguez Montalvo. Era profesora de la UNED, y compartimos, en la amistad, dos predilecciones: por San Juan de la Cruz y por el rey Alfonso X el Sabio. Sagrario, que había publicado una edición del Lapidario, me la regaló con la convicción de que podía sugestionar a un poeta, y que aunque fuese lectura algo pesada también un poeta debe disciplinarse. Yo dejé el libro por ahí hasta que un día me dio por leerlo y me enganchó. Las piedras, las tres culturas medievales (aunque no fueron tres, exactamente)... me dieron materia para dar luego muchos altos de imaginación”. A. S. Pérez-Bustamante (2007), p. 28. ${ }^{36}$ Véase para más información M. F. Reina (2007), pp. 59-75. Pérez-Bustamente ha observado que la autora se aproxima en este libro a la poética de las Crónicas del novelista y poeta gaditano Fernando Quiñones, uno de sus grandes amigos y compañero de generación. ${ }^{37}$ M. F. Reina (2007), p. 66.

38 Yoel Hoffmann habla de una "especie de salvación estética" más que metafísica. Y. Hoffmann (2009), p. 37.
} 
los demás no se desilusionen/ pues de donde resurja es lo mismo y el hecho/ es que está con nosotros. Te saluda y bendice:/ José de Arimatea".

La elegía por la tierra de Cádiz, esbozada en libros anteriores, será una constante en muchos de los poemas de senectud a partir de este libro. ${ }^{39}$ El texto "Piedra fluvial" se articula en torno a algunos de los tópicos más recurrentes de la autora: los vestigios de los pueblos que han hollado y enriquecido el suelo gaditano -"Mi tierra, Asta Regia turdetana,/ alzada entre marismas,/ tierra de polvo oscuro y albarizas,/ polvo de ánforas púnicas y columnas tartesas,/ con tres mil años de esqueleto" (61) - y la etimología árabe del río Guadalete o Río del olvido -" ¡Oh, Wadi Lakka mío, mi río del olvido,/ mi río paraíso, desbórdate y anega!/ ¡Desbórdate e inunda! ¡Desbórdanos y ciéganos/ de olvido nuestros ojos y pon de azul el miedo!// Corre, deja tus márgenes,/apáganos la sed de tantos siglos/ ya que nada ni nadie te lo impide" (62)-. Concretamente, estos versos remiten a los últimos de la composición siguiente titulada "Te necesito por la tierra". El apóstrofe, antes dirigido a un río imbuido de atributos protectores, se encamina a un Tú ausente como en varios de los textos "de crisis" de La torre de Babel y otros asuntos: "Algún rincón habrá ¡altas Medinas!/ ¡Medinas maternales, solitarias!/ Esta madre, la nuestra, ya tiene tres mil años./ Está cansada de mirar al mar, (...) Ya es hora./ Ella Te necesita. Yo también necesito/ que mores en la tierra" (66).

La construcción del espacio mítico-elegíaco del sur se consolida en la segunda parte del poemario "Presencia del sur", donde se poetizan con vehemencia las cicatrices del tiempo y la nostalgia por la tierra natal. En un guiño a la "Canción a las ruinas de Itálica" de Rodrigo Caro, el yo poético camina por un paisaje ruinoso donde reposan los restos de la infancia: "Esto, Fabio, es ni más ni menos lo que queda:/ Tamarindos, begonias,/ gigantescas hortensias:/ Infancia y parvulario" (75). El cielo añorado de Cádiz, primero y último de la poeta, se puebla de pájaros símbolo de la mudanza de estaciones- que conservan todavía el canto (87-88):

\author{
¡Cuántas aves, cuántos años \\ cantándonos mañaneros, \\ locos en la atardecida, \\ en sombras desesperadas! \\ Junto al cántico, dormido \\ te contemplo. Ellos no cambian. \\ Seguirán siendo los mismos: \\ (...) \\ Los pájaros, ay, los pájaros \\ que huyen de nuestro encuentro,
}

\footnotetext{
39 “¿Dónde la feliz tierra prometida/ agotadas ya todas las promesas/ y los edenes prometidos?". P. Paz Pasamar, (1990), p. 47.
} 
que gozan libres, que cantan

su efímera libertad.

Asimismo, el recuerdo de la infancia jerezana de bodegas y viñas se filtra también en algunos versos sueltos como en "Madre monte corona" (91): "Como se huele por primera vez/ en la infancia el aroma del mundo/ y la vida se impregna para siempre,/ yo te olí en las virutas, en el aserradero/ de mi ciudad nativa. La calla Pajarete./ Los toneles. El vino". Además, como en los poemas finales de La torre de Babel y otros asuntos, la poeta se identifica con algunas figuras a las que admira. "En Galicia. A Rosalía de Castro", la poeta gallega y la andaluza conversan en calidad de madres y poetas - binomio indisociable y reivindicado por Paz Pasamaracerca de sus vicisitudes familiares y literarias (95-96): "Henos, Rosalía./ Aquí, como quien dice,/ con carga de hijos y esa/ divina melancolía/ de sabernos y amarnos/ en poesía" (95).

A partir de Philomena ${ }^{40}$ (1995), Balcells advierte en la obra de Pilar Paz Pasamar "unas plasmaciones más amplias, más fecundas y más complejas respecto a sus creencias cristianas y sobre la divinidad" ${ }^{\prime 1}$. El libro se estructura en cuatro momentos del día: alba, mediodía, tarde y noche. La propia creadora ofrece las claves interpretativas de dicha organización, que se corresponde con las edades del hombre o el paso de las estaciones:

En el alba está el amanecer de los pájaros, que antes de nada son los pájaros reales que escucho desde aquí, y luego es la palabra: "Un solo pájaro despierta el universo"... El mediodía es la plenitud, el fruto vital. Es la poesía, el acto de crear y de leer poesía como entrega amorosa al otro, como deseo de ser comido, devorado por el otro... La tarde es la ausencia, el declive. Y la noche, ya se sabe lo que es. Hay poemas que escribí cuando estaba muriendo Carlos: "Eres calor, calor. Tibio regazo"... Para llegar a la conclusión final: “¡Cantar, cantar, cantar es lo que importa!". ${ }^{2}$

El "Génesis" de Philomena, como señala Paz Pasamar, es el despertar a una realidad primigenia, a la creación armónica y musical ${ }^{43}$ : "Anterior al inicio, es

\footnotetext{
40 "Este poemario lo escribí ya en una época muy distinta, de sosiego. Philomena es como el Renacimiento llamaba al ruiseñor y San Juan al alma. Philomena es el alma. El cántico". A. S. Pérez-Bustamante (2007), p. 29.

${ }^{41}$ J. M. Balcells (2009), p. 122.

${ }^{42}$ A. S. Pérez-Bustamante (2007), p. 29.

${ }^{43}$ El poema "Música nuestra" de La torre de Babel y otros asuntos anticipaba el canto venidero de Philomena: "Primera fue, hermana del verbo./ Nacieron en el mismo día,/ crecieron juntos como ramas/ del tronco de la maravilla. (...)/ Hermanas son eternizadas, divinas viejas posesivas/ las dos, tejiendo mano a mano/ un devenir de muerte a vida./ Toldo
} 
decir, desde siempre,/ fue tu aleteo" $(\ldots)$ ¡Eterna y transparente revoloteabas, ibas/ cantadora y exacta!/ Y aunque no le faltara ni un acento a la música/ que añadir, fue tu trino/ quien sonó gratamente y aportó a la Armonía/ de la Creación el verso" (11). Las resonancias pitagóricas y platónicas de estos versos son materia de reflexión continua en los siguientes poemas del libro (19): "Philomena, tu cántico/ es un acorde más entre todos aquellos/ que forman el concierto: oye la sinfonía. $(\ldots) / \mathrm{Tu}$ canto es una nota; una nota entre tantas/ de los innumerables pentagramas, / dentro de la infinita belleza de Su Música". Durante el alba, la poeta entona un canto enérgico y juvenil, repleto de vida y posibilidades. La muerte se percibe como un hecho lejano y sin consecuencias (27): "Te ríes de la muerte, mi ave reprensible,/ no me vengas ahora con tus laúdes gozosos/ y esa manera tuya de ahuyentar los sonidos,/ la amenaza. No mezcles tus airosos gorjeos/ pues jugar a morir es lo que más te gusta". Además de la actitud vital, positiva y "juvenil" del sujeto poético, Philomena relee desde esta postura muchos de los motivos de senectud planteados en obras anteriores. Por ejemplo, en "Sumergida Atlántida" las imágenes de ruinas regresan sin dolor ni llanto, simplemente se descartan, se desechan en beneficio de un coloreado "hodiernismo" (31):

¡Dejemos de escarbar en pueblos sepultados, las ruinas de la Atlántida sumergida, los odres rescatados, los vientres de la tierra!

(...)

Qué menos ni que más que respirar el gozo del azul, reciclados a tierra, hermosamente vivos, de cara a la belleza, ¡busquemos la postura como la buganvilla sobre la cal del muro!

La poesía se concibe en la obra de Pilar Paz como un acto creador ilimitado, puro presente: "Las voces encerradas en paréntesis graves,/ eras, épocas, siglos, años, lustros, $i_{Y}$ sólo/ a ti te basta un día!/ (Pues sólo vivirás un día, Philomena)/ (...) Tú eres la historia y tú su instrumento" (41). No obstante, el mediodía se ve matizado por nuevas formulaciones de la temporalidad como la renovación del ciclo de la vida -"Desde la eternidad/ estábamos, estabas,/ desde ella y hacia ella,/ vamos, estás, estamos,/ ya para siempre rama/ ya para siempre verde/ primavera de mí" (33) - o la incertidumbre de su paso -"y sea tu canto Philomena, ni plenitud ni ruina,/ un trino hacia la luz que se avecina" (42)-. Conforme las horas van transcurriendo, este canto henchido de mediodía irá menguando hasta convertirse en el recuerdo de otros, llevando, incluso, a la posible pérdida del mismo: “¿No era la preferida de tu cántico absorto?/ ¿No compartí tus albas cada vez que llegaste?/

del tiempo, abismo de agua,/ música, cántico, poesía.../ ¡Pan para todos que reparten/ las cosechas de la Armonía!”. P. Paz Pasamar (1982), pp. 80-82. 
Aunque me olvides, sin memoria, vuelve,/ ¿Dónde tu cántico evadido?” (43). La muerte sigue siendo una presencia -cada vez menos- remota: "Si morir fuese sólo la estación/ a la que no importase llegar tarde./ Si la tarde supiera que atardece/ y el hombre que atardece y se hace tarde" (45). A veces la pérdida temida del canto es el peaje obligatorio que hay que abonar en cada acto de creación. El día es el momento iluminador mientras que el atardecer invita a contabilizar lo realizado: "Tan sólo hasta el ocaso-orto dorado/ haremos el balance de los pasos,/ el debe y el haber, el almanaque,/ los signos ortográficos. (...)/ Sólo en la tarde te recibo,/ contable silencioso./ Pago mi cuenta y digo adiós al día" (47).

Finalmente, el crepúsculo es la última y obligatoria parada de Philomena. En principio, fuertes reminiscencias de San Juan de la Cruz abren "la noche" del poemario a la mística áurea -" $i Q u e ́$ bien supiste el relente/ de que Noche te llegaba/ de donde el agua manaba/ y, a pesar de tu ceguera,/ te daba la Luz entera/ y el mundo te transformaba...!" (53)-. Aunque Paz Pasamar no pierde nunca el contacto con "los horrores del mundo", su palabra no se aísla en la experiencia trascendente sino que viene a anunciar el canto del "más allá" o "más allá" del canto: "seremos buena tierra preparada,/ sentiremos que adviene la riada/ abanderada de ternura/ y oiremos cantar a Philomena" (55). En paralelo, la voz senescente de la poeta se advierte en ciertos textos "nocturnos" desengañada, irónica, sazonada con algunas gotas de cinismo: "Auguramos: por ahí se cruzan los malditos,/ habrá asfalto en lugar de morera y magnolio/ y nos sepultarán en el confort de un hoyo" (59); no obstante, a pesar de este desprendimiento de todo optimismo, la noche ya abolida preludia el retorno a la vida del "pájaro fonema": "Estás, alondra, estás, pequeña mía./ Te siento rebullir, saltar, me tienes,/ nos tenemos de nuevo redivivas.// (...) ¡oh, tú mi yo, mi pertenencia,/ oh, tú mi compañera!/ ¡Cantar, cantar, cantar es lo que importa!" (73).

En cierto sentido, el siguiente poemario Sophía (2003) trasciende el alegre gorjeo de Philomena. La voz de la poeta se sabe madura, sabe lo que quiere decir y cómo hacerlo, posee por fin el bagaje necesario para empezar el viaje desde "El hábito canoro" hacia la "Sophía" de las cosas. Las primeras composiciones del poemario enlazan parcialmente con el libro anterior salvo por el hecho de que, en este caso, el canto de Paz Pasamar se percibe más reposado y comedido respecto a la declaración final de Philomena: "debiera, por lo inútil,// ser imposible el cántico./ Sin embargo, detiene/ su pie, desamordaza/ la boca, aspira el aire/ y canta. A veces, canta" (12). En general, los temas del poemario coinciden con el anterior -el concierto universal, el pájaro, el canto-, pero el verso fluye más sereno e invita a la reflexión más que al gozo. Las exclamaciones de júbilo dan paso a las dudas sobre la propia creación poética -“¿Cuál es el repertorio que hoy me toca/ seguir (...)/ Van sonando los pájaros uno a uno y no sé qué dicen" (14)- y al tempus fugit"Fuimos por el camino acumulando/ aire y vacío, objeto sobre objeto,/ (...) esas flores silvestres que el instante marchita/ y hay que tirar apenas concluya la andadura./ Y entonces... ¿Para qué esta pasión de ahora,/ este tenaz deseo de 
perdurar?" (15)-. El tiempo, antes "abolido", transcurre ahora inexorablemente y a su paso sólo queda la nada insignificante de la historia personal (15):
... Se habrá disuelto
el terrón de la tierra que ocupara
ya mi tierra, la saga, la familia, no habrá entronque, todo ello diluido, abocado, volcado en el torrente y si aún la tierra sigue dando vueltas sucedida entre albas y ponientes nada en ella estará de lo que tuve y dispuse y amé y disfruté con otros.

El tono elegíaco y la sensación de la pérdida, la fugacidad del tiempo y de la felicidad impregnan varios poemas de esta primera parte de Sophía como en "Felicidad" o "De rima fácil y cita sabia" - no escapa al lector la ironía de los títulos-. En este último texto, la poeta recurre a algunos de los topoi de la elegía clásica, al Ubi sunt: “¿Qué queda de las cosas?/ ¿Y del hombre, qué queda?// (...) ¿Qué queda de la rosa/ cuando la flor se seca?" (18). El sujeto poético, consciente de los estragos del tiempo, intenta no dejarse arrastrar por ellos y se reafirma en la vida a pesar de la migración de las aves que marcan el comienzo de la estación fría (19):
Mira cruzar las aves, las naves de la esencia huele el olor del agua, deja la vida entera alzar sus largos tallos como una enredadera. Deja de preguntarte si efímera o eterna la ceniza del hombre dónde el viento la aventa. $Y$ vive, vive, vive. Vive con lo que tengas el presente absoluto llevar de cada cuenta. Salda contigo mismo lo que a ti mismo debas y deja hacia el misterio la puerta en par abierta.

La segunda parte de Sophía, "El ámbito sonoro", subtitulado "Viajeras", toma la metáfora del viaje como vía de acceso al conocimiento de ese "misterio que 
embiste" (27). Hay que reseñar la proliferación de poemas centrados en la experiencia del viaje a partir de La torre de Babel y otros asuntos. En los poemas "Knossos" o "Lindos" el paisaje de la antaño floreciente Hélade se puebla de los amarillos jaramagos de Rodrigo Caro y devuelve la poesía de la autora al ámbito de las ruinas, de la decadencia y la elegía: "Artemisa, en lo alto ¿dónde quedó su triunfo/ (...) Dime ¿dónde/ las victorias que incluso la belleza abandona?" (29). Cada título de esta serie remite a un lugar (re)visitado -Parthenon, Cabo Sunio o Jerusalén ${ }^{44}$-, durante la singladura u odisea de Pilar Paz hasta llegar al amado "Paraíso" nativo (39): "Ésta es mi luz, lítica cuna mía,/ tarde llego y despacio a acogerme en tus piedras/ paraíso de grama, grazalumbre./ Al fin, la sombra en paz,/ la paz, la tierra...”. Es reseñable que ese sentimiento de elegía que impregna buena parte de los poemas "mediterráneos" desaparece en los textos "americanos" de la poeta gaditana. ${ }^{45}$ En ellos, Paz Pasamar encuentra una prolongación del "sur remoto" que se manifiesta elocuentemente en el cierre del poema "Tarde en Jibara": "Huele a eterno. Siempre a eterno en Jibara" (33).

La tercera parte "es la más desnuda, más descarnada en el sentido literal de dejar la carne y dejar hablar al espíritu" ${ }^{\text {"46 }}$, un lugar abonado para la sabiduría; sin embargo, la voz poética no puede dejar de sonreír maliciosamente gracias al distanciamiento que progresivamente va adquiriendo el sujeto poético en sus últimos escritos. En principio, apostrofa al abuelo -"hombre sabio entre sabios"-, figura tradicionalmente vinculada a la custodia y transmisión del conocimiento, y le reclama que se guarde la sabiduría "bajo siete cerrojos" para afirmar después que no sabe qué hacer con ella: "Rebusco en tus palabras qué sobre el abandono.../ No sé qué hacer ni donde colocar esta llave./ Si es la sabiduría... ¿Ya para qué me sirve?" (44). ${ }^{47}$ En la línea desengañada e irónica de esta sección, destaca el significativo poema "Erosiones" (48-49) que presenta un Eros apolillado, impotente, viva

${ }^{44}$ Los poemas dedicados a Jerusalén "Muro del llanto", a "Nicaragua" -en La torre de Babel y otros asuntos aparece publicado un poema de temática semejante: "Niño maya"-o a "Rota" muestran una línea comprometida con el aquí y ahora que rara vez tiene cabida, salvo puntuales excepciones, en el conjunto de la poesía de Pilar Paz Pasamar.

${ }^{45}$ Se ha publicado en la colección "Cuadernos de Kronión" dirigida por Nieves Vázquez Recio Poemas americanos (2012b), una hermosa edición de cien ejemplares numerados ilustrada por Arturo Redondo, hijo de Pilar Paz Pasamar, donde se recogen los poemas de tema americano seleccionados de los libros La torre de Babel y otros asuntos (1982) y Sophía (2003).

${ }^{46}$ M. F. Reina (2007), p. 72.

${ }^{47}$ Simone de Beauvoir, al teorizar sobre la experiencia de la vejez, más que abogar por esta visión "ingenua" del conocimiento, arguye que la ancianidad libera al ser de las ilusiones juveniles: "En el plano intelectual, la vejez también puede ser liberadora: libra de las ilusiones. La lucidez que trae consigo va acompañada de un desencanto que suele ser amargo. En la infancia y en la juventud, la existencia es vivida como un ascenso (...). De pronto uno descubre que no va a ninguna parte, sino a la tumba". S. Beauvoir (1989), p. 581. 
imagen de los estragos producidos por sus largos años: "Eros, y su ala rota,/ emboladas las puntas de sus flechas/ con alcanfor y trapo,/ y en el carcaj un agrio bocadillo,/ mochila al hombro, el niño./ Se le cayó la venda/ desapretada y pudo/ mirar en derredor con los ojos viejísimos".

Como se ha visto anteriormente en algunos versos de La torre de Babel, la finitud del ser humano no se concibe como una sombra acechante sino como umbral y fuente de conocimiento. El trabajo del tiempo, la muerte, el cambio o el envejecimiento son personajes inevitables de aquello que se ha llamado vida y que, gracias a la memoria, puede sortear el aniquilamiento. De esta suerte, la composición final de Sophía revisita el "Río del olvido" de Textos lapidarios (5051). No obstante, sorprendentemente, en su ribera la hablante poética escucha "la eternidad que al otro lado clama" (51), la necesidad de permanecer en el ahora, de sentir la "plenitud de lo efímero" como bien podría suscribir uno de los pensadores de referencia de la jerezana, Gaston Bachelard: "en todo poema verdadero se pueden encontrar los elementos de un tiempo detenido, de un tiempo que no sigue el compás, de un tiempo al que llamaremos vertical para distinguirlo de un tiempo común que corre horizontalmente". ${ }^{48}$

En 2008 se publica el último poemario hasta la fecha de Pilar Paz Pasamar, Los niños interiores. La obra se divide en dos secciones que parecen sugerir conceptos antitéticos: la primera, de mayor extensión, se titula "Los niños interiores"; mientras que la segunda, "Externidades", posee un carácter más introspectivo. En la primera parte del libro, el sujeto poético trata de recuperar a sus niños interiores, expresión máxima de esa capacidad de asombro y emoción ante la realidad que suele disminuir con la edad, y revelada de manera excelente en el siguiente poema: "En la inocencia ciega y luminosa/ del pensamiento, enardecida/ por su poder, sus pausas y paisajes,/ en la inocencia plena y absoluta,/ en desnudez, en cueros,/ ya solo el balbuceo nos precede,/ ya atónitos miramos a las cosas/ con pupilas de estreno" (31). Asevera Díez de Revenga que "en toda poesía de senectud hay un espacio para la propia auto-observación, para el propio análisis y para el intento de comprensión de una identidad, con la que se ha vivido muchos años, pero que la edad ha transformado". ${ }^{49}$ La visión de la experiencia pasada -"sombra hacia atrás y hacia delante" (29) - se ajusta a este tipo de poesía de senectud que echa la vista atrás y observa el camino recorrido con mirada crítica. En este sentido, "Fracaso escolar" es un apóstrofe de la poeta ya entrada en años a esa "niña evaluada" por el tiempo ido, por las oportunidades desaprovechadas, por las energías consumidas infructuosamente, que dialoga en el tiempo con la poeta-madre de La torre de Babel y con la "niña genial" de las tertulias madrileñas (21):

\footnotetext{
${ }^{48}$ G. Bachelard (1999), pp. 93-94.

${ }^{49}$ M. F. Reina (1988), p. 76.
} 
Mira, niña evaluada, en el panel del tiempo.

Tu nombre no figura o ha desaparecido.

No fuiste a clase nunca.

Anduviste perdida dilapidando el oro,

(...)

La gente te gritaba

que alzaras las clavijas y sonaras más fuerte

porque no se te oía de tan cabizbajuna

y tanto andar sin orden ni concierto.

Tu nombre no figura en la lista de accesos

al porvenir. Tú nunca lo tuviste.

Ya te vas, y no estás ni siquiera empezada.

Ya se ha comprobado en algunos textos del poemario anterior que la vejez se manifiesta en Paz Pasamar como un distanciamiento irónico en el poema. De esta guisa, en "Me burlo de Minerva" (33), la diosa de la sabiduría aparece ataviada como una caricatura inerme -"Minerva, sabia mía, qué imponente resultas/ búho y cimera - caída ya de bruces/ ante este niño chico"- a pesar de toda su sabiduría frente al niño "que no sabe nada de nada" de la sabiduría "inocente" e intuitiva del niño, hay que añadir la sensación de naufragio en un mar informatizado. Las nuevas tecnologías han acelerado dramáticamente los ritmos biológicos y cognoscitivos del individuo. La poeta jerezana siente que esta velocidad suprime el carácter sagrado de la palabra escrita: "Pero ellos, los árboles, hoy se han puesto a escribir,/ con plumillas de aquellas que portaban los cofres/ de los niños pues quieren dedicar su madera/ a estuches sapienciales, antes que ágrafo el mundo/ olvide la escritura" (25).

Paradójicamente, en Los niños anteriores el "final de la travesía" acerca a la poeta "al principio", a los niños-pájaros que siempre habitaron su pecho. ${ }^{51}$ No hay dudas o miedos, sólo amor. Amor por los suyos, restaurador y fin último, la vía unitiva del místico, el reencuentro y fusión en lo absoluto: "En ti me muevo, existo y soy/ intrauterino y placentario,/ nado en tu líquido y me nutro,/ vivo y circulo en tu regazo./ (...) Me parirás, darás a luz,/ llegaré a ser -y no sé cuándo-,/ parte de Ti, de la luz misma,/ de lo infinito y lo creado" (45). Por el contrario, la última sección

\footnotetext{
50 Cfr. "Es la sabiduría” P. Paz Pasamar (2003), p. 44. Ya en La torre de Babel y otros asuntos expresa una cierta desconfianza al respecto: "La pluma de un jilguero es más robusta/ que todas las certezas". P. Paz Pasamar (1982), p. 16. Salvando las distancias, este escepticismo recuerda en cierto modo al Vicente Aleixandre de Poemas de la consumación: "Así niños y hombre/ pasan. El hombre duda./ El viejo sabe. Sólo el niño conoce./ Todos miran correr la cola vivida". V. Aleixandre (1968), pp. 55.

51 "Me asusta el eco, me asusta el mundo, me asusta el hombre,/ me asusta todo menos la muerte, todo me asusta./ Y así, sentada y contemplativa, así les canto./ Y ellos me cantan, me cantan pájaros dentro del pecho”. P. Paz Pasamar (2008), p. 44.
} 
del libro - "Externidades"- aborda la experiencia de la memoria en relación con el paso del tiempo. En el intenso poema que inaugura la sección, el punto de vista del niño, sus experiencias ingenuas de "niña de la guerra", colisionan con la realidad que el mayor conoce. La poeta-niña se solaza despreocupadamente en medio de la desolación más profunda (51-52):
Cuando íbamos allí, donde estuvo la guerra que ya había pasado y no estaba delante pero sí su vestigio y esqueleto y un socavón enorme donde había estallado una bomba y me dijeron que allí murieron muchos, se me clavó en la boca el pan con chocolate. (...) Perseguíamos pájaros que buscaban asilo en lo alto de tapiales, donde las lagartijas se introducían rápidas por todos sus resquicios, jugar a rescates, a saltar entre piedras y cascotes y luego, sudorosos sentarnos en el suelo mientras las vigilantes del brazo de los hombres las acompañaban buscaban escondites entre las ruinas.

De otro orden, la composición "La mirada del hijo", subtitulada sintomáticamente "Bifurcación", es un ejemplo excelente -y tardío- de inversión de la mirada ascendente de la niña-madre sobre la que trabajó Paz Pasamar en sus primeros poemarios $^{52}$ : "Me sentí encanecida desde aquella mirada/ pero por ella supe la edad que poseía" (63). La mujer mayor, presumiblemente en el rol de mentora, no puede hacer otra cosa que contemplar cómo el discípulo amado se marcha "ya sin retroceso". La temporalidad vivida con resignación por esa edad conocida a través del otro no se corresponde con el tono general de los poemarios de senectud de la escritora jerezana. En cambio, en este poemario trasciende una visión positiva y esperanzada de la estación dorada -"Dulce oro viejo"- entendida como reconciliación con el presente e ilusión por un porvenir libre de temores (65):

Nada más pleno y fuerte que este oro sencillo recubierto de láminas de antiguas primaveras

\footnotetext{
${ }^{52}$ Por ejemplo, en su primer poemario Mara es posible encontrar versos como los siguientes: "Madre, tú eres ya, no tuya, sino mía./ Te has ido dando como la luna sobre el agua./ Toda tu claridad se ha reflejado/ inmensa sobre mi alma// Madre, ya no eres tú, tu risa no es tu risa,/ soy yo quien te sonríe, quien te mueve las manos/ quien te vive y respira por ti”. P. Paz Pasamar (1951), p. 19.
} 


\begin{abstract}
(...)
El oro derretido, tan puro y tan caliente, ebrio en la pleitesía de la estación dorada, frente a tanta belleza nos acerca al principio, al amor inicial escondido en espera, a la alquimia del beso, a la definitiva cita restauradora, final de travesía, inicio de otro gozo, plenitud infinita, retornada a los dedos orfebres que ya esperan transformar la materia de amor que se avecina.
\end{abstract}

El poema en prosa con el que finaliza Los niños interiores profundiza todavía más en esta idea. "El día de mañana" (69-71) niega un tiempo que no es presente, ni pasado ni futuro; sino un limbo acrónico y atópico donde todo el cosmos vive en comunión una eterna "primavera inmarchitable" (71):

Sentirse propietaria de ilusión cuando ya no preocupa su adquisición forzosa ni la ansiedad de incrementarla. Estado puro del sobrevivir sin soporte, oh, qué libertad extraordinaria, qué luz riquísima la del poniente, su asequible sombra hacia la que nos encaminamos desde el tiempo de nunca jamás hasta la primavera inmarchitable.

\title{
4. Conclusiones
}

No es tarea fácil extraer todas las conclusiones posibles sin el espacio para analizar de manera íntegra la producción poética de Pilar Paz Pasamar, compuesta por once libros con casi sesenta años de diferencia entre la revelación de Mara y la "senectud" de Los niños interiores. ${ }^{53}$ Evidentemente, la poesía de Pilar Paz envejece junto a la autora y, en consecuencia, la conciencia del paso del tiempo va a influir en el tono y los temas de sus últimos poemarios. Como señala Keefe Ugalde: "sabemos que estamos necesitados de prolongación y aplazamiento urgentes y nos rebelamos contra la nostalgia y la cronología"..$^{4}$

La obra poética de senectud de Pilar Paz Pasamar, más que reflejar ese doble patrón de envejecer, se corresponde a la perfección con la actitud denominada por

\footnotetext{
${ }^{53}$ La poeta jerezana, preguntada por su trayectoria, responde en los siguientes términos: "Puedo decir que en mi obra se plasman distintas épocas que recogen, tanto aspectos herméticos y filosóficos, más cerca de la temática del misticismo, como aspectos de la realidad que me rodeaba en un momento determinado. He combinado la poesía culturalista y mística, pero la he intercambiado con la poesía que habita lo cotidiano, lo familiar, las pequeñas cosas $\mathrm{y}$, sobre todo, hechos reales que me sobrecogieron en un momento determinado". C. Bados Ciria (2005).

${ }^{54}$ S. Keefe Ugalde (2007), p. 394.
} 
los especialistas en psicología de "Gerotrascendencia", 55 que se manifestaría "por medio de cambios de la persona en el tiempo y en el espacio, por medio de un incremento de la afinidad con generaciones anteriores y futuras, por un desaparecer del temor a la muerte y por una aceptación de la 'dimensión del misterio' que hay en la vida" ${ }^{56}$. La religiosidad de Paz Pasamar, como también apunta Díez de Revenga en el caso del poeta santanderino Gerardo Diego, influye directamente en sus composiciones de senectud, al dotar a sus versos de un sentido teleológico "de esperanza en un futuro metafísico más allá de la muerte y una espiritualidad desmitificadora de realidades vitales como pueden ser la edad o la muerte". ${ }^{57}$

La llegada de la madurez y la senectud inaugura una voz oscilante entre dos vertientes. Por un lado, se percibe una línea, al estilo de Jorge Guillén, de exaltación y prédica de una vejez positiva y laboriosa. ${ }^{58} \mathrm{La}$ voz en ese otoño dorado es entusiasta; el timbre agudo, pura potencia; la muerte no asoma en los versos crepusculares de Pilar Paz Pasamar. El tiempo se estanca en un perpetuo presente o en imágenes cíclicas de renovación: "Frente a la noche inmensa, frente a los altos riscos,/ donde todo lo vivo bulle y cambia y se transforma,/ la ceniza y el hueso son abono fecundos, / fango y piel del detritus que se hará primavera" 59 . Por otro lado, la voz de la mujer mayor, ligada a una geografía sentimental -Cádiz- marcada por el retorno y la nostalgia, se somete al escrutinio, a veces inclemente, de la memoria: "No sé si fueron útiles aquellas enseñanzas y la concienzuda preparación de nuestros mayores para ese gran día del mañana, al modo de quien prepara el ajuar para el día de bodas" ${ }^{\prime 60}$.

Para terminar quisiera destacar la recurrencia de un curioso patrón aplicable a Pilar Paz Pasamar y a varios de sus compañeros generacionales de Platero, "el brazo sureño de la generación poética del 50"61: aislamiento y tradición en los autores más periféricos (José Luis Tejada, Julio Mariscal) y presencia más palpable de las nuevas tendencias en los autores del "centro" (José Manuel Caballero Bonald, Fernando Quiñones). La poeta jerezana oscila entre lo aprendido en sus años de formación durante la efervescencia cultural madrileña y la experiencia del

55 Concepto tomado de Lars Tornstam (1989): 55-63. Más información en Lars Tornstam (2005).

${ }^{56}$ U. Lehr, H. Thomae (2003), p. 105.

${ }^{57}$ F. J. Díez de Revenga (1988), p. 130.

58 Véase los hermosos versos de Jorge Guillén citados por Díez de Revenga que se corresponden a la quinta sección del poema "De la edad": "Vejez en Calderón, vejez de Goethe/ Apasionada ancianidad fecunda/ Por la vía suprema del esfuerzo/ Diario, competente,/ Aunque inseguro en busca de otra cosa,/ No lejos ya del último horizonte". F. J. Díez de Revenga (1988), p. 68.

${ }^{59}$ P. Paz Pasamar (2008), pp. 13-14.

${ }^{60}$ P. Paz Pasamar (2008), p. 70.

${ }^{61}$ J. R. Ripoll (1986), p. 9. 
regreso en 1957 a su patria chica. Este hecho provocará un ahondamiento en un universo genuino imbuido por las lecturas de los grandes maestros (Juan Ramón Jiménez, Santa Teresa, San Juan de la Cruz) y por una mirada amable e indagadora hacia lo cotidiano. No obstante, a continuación de esa implosión de lo pequeño trascendente plasmada en La soledad contigo y el anhelo de ruptura que supuso Violencia inmóvil, adviene el silencio y la voz de Pilar Paz busca nuevos derroteros: la apertura al otro prefigurada en la Torre de Babel y otros asuntos; el refugio e intento de autocomprensión a través de la historia en Textos lapidarios; el canto y la ascesis sapiencial en Philomena y Sophía y la eterna voz de esos niños interiores que luchan por ser oídos. En mi opinión, son esos niños que regresan de comer pan con chocolate, de jugar a estar muertos y, sobre todo, los que aguardan "el día de mañana", quienes mejor reflejan la evolución de la poesía de senectud de Pilar Paz Pasamar: una poesía hecha de memoria, tiempo y carne que, aun sabiendo que pronto serán sombra, polvo, nada, "vive como un regalo el hoy apasionadamente" ${ }^{62}$.

\section{Obras citadas}

AleIXANDRE, Vicente: Poemas de la consumación, Barcelona, Plaza y Janés, 1968. BACHELARD, Gaston: La intuición del instante, México, F.C.E, 1999.

BAdos Ciria, Concepción: "Pilar Paz Pasamar: poesía y vida", en Pilar Paz Pasamar, sección "Nombres propios" del Centro Virtual Cervantes del Instituto Cervantes, 2005 [en línea], $<\mathrm{http}: / /$ cvc.cervantes.es/actcult/paz_pasamar/entrevista.htm $>$ [Consulta: $12 / 04 / 2011]$.

BALCElls, José María (ed.): Ilimitada voz: Antología de poetas españolas 19402002, Cádiz, Universidad, 2003.

-----: Voces del margen. Mujer y poesía en España, León, Universidad, 2009.

BEAUVOIR, Simone: La vejez, Barcelona, Edhasa, 1989.

BORGES, Jorge Luis: La cifra. Madrid: Alianza, 1981.

BUTLER, Robert N.: "Age-ism: Another Form of Bigotry", The Gerontologist, 9 (1969), pp. 243-246.

CALles Moreno, Juan María: La modalización en el discurso poético, Alicante, Biblioteca Virtual Miguel de Cervantes, 2002, [en línea], $<$ http://www.cervantesvirtual.com/obra/la-modalizacion-en-el-discursopoetico--0/> [Consulta: 13/03/2011].

CIPLIJAUSKAITÉ, Biruté: La construcción del yo femenino en la literatura, Cádiz, Universidad, 2004.

${ }^{62}$ P. Paz Pasamar (2008), p. 69. 
DíEZ DE REVEnGA, Francisco J.: "Vicente Aleixandre, poeta de la consumación", Monteagudo, 59 (1977), pp. 39-46.

-----: Poesía de senectud: Guillén, Diego, Alexandre, Alonso y Alberti en sus mundos poéticos terminales, Barcelona, Anthropos, 1988.

-----: "Unamuno poeta: en torno al 'Cancionero' como poesía de senectud", en Dolores Gómez Molleda (ed), Actas del Congreso internacional cincuentenario de Unamuno, Salamanca, Universidad, 1989, pp. 441-446.

GUTIÉRREZ ESTUPIÑÁN, Raquel: "Sobre la configuración de la vejez en la escritura femenina", en Rosaura Hernández Monroy y Manuel F. Medina (coords.), La seducción de la escritura. Los discursos de la cultura hoy: 1996, México, Fideicomiso para la Cultura México/Estados Unidos, 1997, pp. 152-163.

HoffmanN, Yoel (ed.): Poemas japoneses a la muerte. Escritos por monjes zen y poetas de haiku en el umbral de la muerte, Barcelona, DVD, 2009.

KeEFE UGALde, Sharon: En voz alta. Las poetas de las generaciones 50 y 70. Antología, Madrid, Hiperión, 2007.

LeHr, Ursula y Hans THOMAE, Psicología de la senectud. Proceso y aprendizaje del envejecimiento, Barcelona, Herder Editorial, 2003.

LIPOVETSKY, Gilles: La era del vacío. Ensayos sobre el individualismo contemporáneo, Barcelona, Anagrama, 2011.

LóPez CABrales, María del Mar (ed.): Pilar Paz Pasamar. Marinera en tierra adentro, Cádiz, Ediciones Presea, 2012.

PAZ PASAMAR, Pilar: Mara, Madrid, s.n. [Imprenta Altamira], 1951.

-----: Los buenos días, Madrid, Rialp, 1954.

-----: La soledad contigo, Arcos de la Frontera (Cádiz), Ed. Jerez Industrial, 1960.

-----: La mujer y la poesía de lo cotidiano, Madrid, Editora Nacional-Bolaños y Aguilar, 1964.

-----: Violencia inmóvil, Madrid, Ágora, 1967.

-----: La Torre de Babel y otros asuntos, Cádiz, s. n. [Imprenta Ingrasa], 1982.

-----: Poemas lapidarios en Textos lapidarios. La dama de Cádiz. Poemas, Cádiz, Fundación Municipal de Cultura-Cátedra "Adolfo de Castro", 1990.

-----: Philomena, Sevilla, Fundación El Monte, 1995.

-----: Sophia, Sevilla, Ed. Distrito del Sur \& Ayuntamiento de Sevilla, 2003.

-----: “Ocho poemas inéditos", RevistAtlántica de Poesía, 31 (2007), pp. 45-49.

-----: Los niños interiores, Madrid, Calambur, 2008.

-----: Ave de mí, palabra fugitiva (Poesía 1951-2008), Ana Sofía Pérez-Bustamante (ed.), Cádiz, Diputación Provincial, 2012a.

-----: Poemas americanos, Madrid, Del Centro Editores, 2012b.

PÉrez-Bustamante Mourier, Ana Sofía: "Alquimia de saber, voz de Pilar", en Pilar Paz Pasamar, sección "Nombres propios" del Centro Virtual Cervantes del Instituto Cervantes, 2005 [en línea] 
$<$ http://cvc.cervantes.es/actcult/paz_pasamar/obra/perez.htm $>$ [Consulta: 23/04/2011].

-----: "La corriente infinita. Una vida con Pilar Paz Pasamar (entrevista)", RevistAtlántica de Poesía, 31 (2007), pp. 15-33.

REINA, Manuel Francisco: «Juan Ramón y la niña que hablaba con Dios», $A B C D$ las artes y las letras, 730 (2006), pp. 10-11.

-----: "Pilar Paz Pasamar, una poeta de tradición andalusí", en Pilar Paz Pasamar, El río que no cesa, Jerez, EH Editores, 2007, pp. 59-75.

RIPOLL, José Ramón (ed.): La alacena, Jerez, Eds. Diputación Provincial de Cádiz, 1986.

-----: "El archipiélago poético de Pilar Paz Pasamar", RevistAtlántica de Poesía, 31 (2007), pp. 3-14.

SonTAG, Susan: "The Double Standard of Aging", Saturday Review of the Society, 23 de septiembre (1972), pp. 29-38.

TORNSTAM, Lars (1989): "Gero-transcendence: a reformulation of the disengagement theory", Aging, 1 (1989), pp. 55-63.

-----: Gerotranscendence: A Developmental Theory of Positive Aging, New York, Springer Pub. Co, 2005. 